\title{
JOSÉ LUIS GÓMEZ URDÁÑEZ, El marqués de la Ensenada, el secretario de todo, Punto de Vista Editores, Madrid, 2017.
}

José Luis Gómez Urdáñez venía cercando al marqués de la Ensenada desde hace años, ya sea con su propia flota (sus libros sobre El proyecto reformista de Ensenada de 1996 y sobre Fernando VI de 2001 y sus cada vez más numerosos artículos sobre los personajes de su entorno), ya sea con escuadras salidas de sus arsenales de la Universidad de la Rioja, como las capitaneadas por Cristina González Caizán (La red política del marqués de la Ensenada, de 2014) o por Diego Téllez Alarcia (Don Ricardo Wall. Aut Caesar aut nullus, de 2008), ya sea finalmente con algunos otros barcos navegando con registros sueltos por los mares de las revistas especializadas. Así que ya había llegado la hora de capturar a la presa principal de la operación, es decir de acometer la biografía del propio Don Zenón de Somodevilla.

Y el catedrático y académico riojano lo ha hecho a su muy personal estilo, en una obra al mismo tiempo erudita y desenfadada, profunda en la atención a las graves cuestiones de la vida política del momento y ligera con aire minué a la hora de referir las mil y una vicisitudes de las relaciones personales mantenidas por el ministro con su entorno de secretarios, funcionarios, cortesanos amigos e incluso enemigos, o de pintar al pastel la vida cotidiana de su biografiado cuando se entregaba a sus celebradas cenas madrileñas o a sus musicales paseos en Aranjuez, antes de procurarse dorados exilios en Granada, El Puerto de Santa María o Medina del Campo cuando sus enconados rivales le ganaron la partida y perdió el favor real.

Así, encontramos primero lo que se esperaba: una valoración de su obra de gobierno en aquellos terrenos que fueron objeto privilegiado de su atención desde los múltiples ministerios desempeñados como "secretario de todo": marina y hacienda en primer lugar. Ahora bien, el repaso que se hace a su actuación estelar en estos ramos no resulta una síntesis ecléctica al uso, sino una solvente disección sostenida por el dominio de las fuentes originales, entre las que destacan las obtenidas de las correspondencias oficiales y privadas del ministro o intercambiadas entre los personajes que le rodearon tanto amigos como enemigos. Y así se dedica un capítulo entero a su labor en el ámbito de la Armada, quizás el más conocido desde la obra de Cesáreo Fernández Duro (con su famoso vítor de "Paso al Genio"): promulgación de las ordenanzas de Marina y 
de Bosques, imposición de la Matrícula de Mar, espionaje industrial confiado a los dos grandes marinos y científicos Jorge Juan y Antonio de Ulloa, atención a la formación de oficiales en la Academia de Guardiamarinas, impulso a la construcción naval (mediante el recurso al "sistema inglés", luego adaptado a las necesidades españolas), todo un completo programa que llegaría a concitar la alarma de las autoridades inglesas y el llamamiento a derribar por todos los medios al entregado ministro.

Porque, en efecto, Ensenada se volcó a fondo en sus proyectos, empleando una asombrosa energía en llevar a cabo sus propósitos contra el viento de los rivales y la marea de la desidia administrativa. Así lo hemos visto en el caso de la Armada, pero lo podemos corroborar en el establecimiento del Real Giro, el banco oficial para los pagos exteriores, y sobre todo, de una forma ejemplar, en su lucha por la implantación del catastro, que si bien no alcanzó su objetivo, sí que pudo legarnos una radiografía completa de la economía y de la distribución de la riqueza en las provincias castellanas a la altura de mediados de siglo, gracias a una titánica empresa que todavía hoy causa perplejidad y admiración por su enorme envergadura y por el sobrehumano esfuerzo que supuso la realización de la magna encuesta, tal como se puede contrastar a partir de la ingente documentación conservada en los archivos, aunque al final se topara, como en otros casos, con la enemiga de los que se sentían perjudicados por el sistema fiscal al que debía servir de base, la Única Contribución. En cualquier caso, la descripción del proceso que se realiza en el libro mantiene al lector en suspenso por la insólita capacidad del autor de hacernos algo así como copartícipes de la empresa doscientos cincuenta años después.

El proyecto político de Ensenada superó la cárcel de papel en que pudo haber quedado prisionero gracias a la implementación de un complejo entramado de apoyos y de connivencias, fundamentado casi siempre en la conformidad de sus colaboradores con el mismo, es decir en la coincidencia ideológica, y a veces, inevitablemente, también en la lógica egoísta de la autopromoción personal. Esta red, pacientemente tejida por el ministro, es lo que el autor ha definido acertadamente como el "partido ensenadista", integrado por personajes que ocupaban cargos oficiales, altos o no tan altos, o por otros amigos que podían hacer valer la influencia de su pluma o de sus relaciones. La descripción de la compleja articulación de este círculo que se disponía en torno a Ensenada pero cuyos componentes mantenían conexiones asimétricas con el núcleo central encarnado por el maestro del juego, es uno de los mayores logros del libro, pues dar una visión segura implica conocer íntimamente a cada una de las piezas y el papel que respectivamente desempeñaron en cada momento, en cada coyuntura.

Y esta es una de las cosas que más impresionan durante la lectura del libro. El autor se mueve por los salones, por las tertulias, por los mentideros, por los despachos, por las covachuelas, por los pasillos de los palacios, como si fuera un Ensenada redivivo (con su peluca y su casaca, como lo retratara Jacopo Amiconi), dándonos cumplida cuenta de cada uno de las personas que nos 
va presentando, de sus funciones, del trato que debemos tener con él, de sus virtudes o sus debilidades, a veces hasta de sus intimidades. Da la impresión de que el autor se ha encontrado a sus personajes viendo una comedia en el teatro del Príncipe o de la Cruz o ha departido con él mientras navegaba por las aguas del Tajo con la voz de Farinelli como fondo musical o ha compartido alguna vez una jícara de chocolate caliente de las que después pintaría con su mágica poesía Luis Meléndez. La sensación de vida, de realidad, de cotidianeidad que ofrecen las hechuras (o los rivales) del marqués es algo sin parangón en la historiografía española.

Semejante puesta en escena nos Ileva a otro de los aciertos de la obra. El autor ha asimilado como pocos la absoluta necesidad de articular las relaciones entre el gobierno y la corte a la hora de analizar las contingencias del ejercicio del poder, a la hora simplemente de hablar de política. En el Antiguo Régimen el rey no era una figura decorativa, sino la persona que debía avalar todas las decisiones del gobierno, por lo que tenía que ser cortejado (nunca mejor dicha la palabra), aconsejado, manipulado o engañado por sus colaboradores y subalternos. De ahí que la proximidad al rey (y a la reina, como bien se subraya en la obra) fuera una fuente de poder. De ahí que esa proximidad se buscara bien en la intimidad del cuarto del rey (donde pululaban mayordomos y sumilleres), bien en el despacho directo cara a cara de los asuntos de gobierno por parte de cada secretario de Estado. Esta dualidad entre el gobierno y la corte se pone especialmente de relieve con motivo de la caída de Ensenada, una conspiración palaciega en toda regla, urdida por ministros (Ricardo Wall) y embajadores (Benjamin Keene), pero también por cortesanos como el odioso duque de Huéscar (luego de Alba), nombrado mayordomo mayor de Fernando VI, prominente miembro de la facción anglófila y enemigo encarnizado del marqués, que valiéndose de su fácil acceso al rey pudo convencerle de la veracidad de las falsas pruebas (que nunca se encontraron) sobre la supuesta guerra declarada por Ensenada en el Caribe.

Ensenada sale (con justicia) muy bien parado de la investigación expuesta a lo largo de las páginas del libro. Sin embargo, nada más erróneo que pensar en una hagiografía. El autor destaca en más de una ocasión la falta de escrúpulos de ese ejemplo de "déspota ilustrado" que fue Ensenada a la hora de llevar a cabo sus proyectos. El mundo en que se desenvolvía exigía una fuerte dosis de vigilancia y de energía para capear el temporal de conspiraciones, asechanzas y resistencias ante las medidas adoptadas por el "secretario de todo". Ahora bien, hubo ocasiones en que el déspota, amante del bien público y de las reformas moderadas, dio pruebas de una utilización imperturbable de la "mano dura" (por ejemplo, en ocasión de la represión de la revuelta venezolana ordenada desde su despacho y ejecutada en el terreno por Julián de Arriaga), de una abierta satisfacción por la venganza (como ocurrió con la persecución inquisitorial contra Pablo de Olavide Ilevada a cabo con la complacencia de sus enemigos y la connivencia de Carlos III) y hasta de una inexcusable crueldad, como en el caso, bien documentado, de la persecución que desatara contra la comunidad 
gitana, a la que trató de exterminar por todos los medios, conduciendo a sus miembros al encierro o al trabajo forzado en los lugares más inhóspitos (como las minas de Almadén), dando muestras de una obstinación tal que no llegó a ser compartida ni siquiera por algunos de los obligados cumplidores de sus órdenes y que permite hablar con toda propiedad de un auténtico intento de genocidio.

José Luis Gómez Urdáñez nos ha entregado así una obra que reúne en alto grado dos cualidades que rara vez suelen ir de la mano. Por un lado, el rigor científico, basado en una familiaridad asombrosa con las fuentes, en un pleno conocimiento del contexto y en una interpretación a la vez equilibrada y atrevida de los datos a su disposición. Por otro lado, una espontaneidad y una inmediatez en el tratamiento de los hechos que imprimen una vivacidad inusitada al relato, que alcanza un alto grado de amenidad, gracias a un profuso anecdotario siempre significativo. Si a ello le añadimos una indiscutible galanura literaria, una utilización más que oportuna de los testimonios directos y un desacomplejada desenvoltura en el vocabulario (a menudo con su punta de humor), nos hallamos ante una obra à tout lire, empleando si se nos permite el francés utilizado como lengua franca en la época.

Es una obra, además, que nos hace meditar, melancólicamente, sobre el presente, cuando vemos los extenuantes esfuerzos del marqués por introducir la racionalidad en la obra de gobierno y por superar los arraigados prejuicios de sus coetáneos. En este horizonte, sentimos incluso una punzada de pesimismo cuando, mirándonos en el espejo del siglo XVIII, constatamos la dificultad que, desde el Antiguo Régimen y hasta nuestros propios días, tiene este país para suprimir la lacra de los privilegios, del nepotismo (Ilamado "capital relacional" con uno de los eufemismos mistificadores hoy al uso), del favoritismo, de la promoción de los más ineptos a los más altos cargos, de la corrupción institucional o de la sensibilidad de papel de lija de los poderosos ante las necesidades del conjunto de la sociedad. Bienvenida sea por tanto esta excelente biografía del marqués de la Ensenada, obra de madurez de uno de nuestros mejores historiadores actuales.

Carlos Martínez Shaw UNED cmshaw@geo.uned.es 